\title{
Comparison of Trypanosoma cruzi infection in dogsinoculated with blood or metacyclic trypomastigotes of Berenice-62 and Berenice-78 strains viaintraperitoneal and conjunctival routes
}

\author{
Comparação da infecção pelo Trypanosoma cruzi em cães inoculadoscom sangue \\ em tripomastigotas uretacíclicas de cepas Berenice-62 e Berenice-78, \\ pelas vias intrapentoneal e conjuntival
}

\author{
Maria Terezinha Bahia1, Washington Luiz Tafuri', Marcelo Vidigal Caliari², Vanja Maria Veloso', \\ Cláudia Martins Carneiro ${ }^{3}$, George Luiz Lins Machado Coelho ${ }^{4}$ and Marta de Lana ${ }^{3}$
}

\begin{abstract}
This paper aimed to verify the influence of the inoculum source (blood or metacyclic trypomastigote) and the route of inoculation (intraperitoneal or conjunctival) on the course of T. cruzi infection in dogs, using comparatively the T. cruzi strains Berenice-62 and Berenice-78. All dogs inoculated intraperitoneally became infected independently of the T. cruzi strain and source of trypomastigotes used. High level of infectivity was also observed when metacyclic trypomastigotes of both strains were inoculated by conjunctival route. However, when blood trypomastigotes were inoculated by conjunctival route the percentages of infectivity were significantly lower in dogs inoculated with both strains. Parasitaemia was significantly higher in animals infected with metacyclic trypomastigotes via the conjunctival route independently of the T. cruzi strain used. All animals infected with Berenice-78 strain showed severe acute myocarditis. On the other hand, animals infected with Berenice-62 showed severe acute myocarditis only when infected with metacyclic trypomastigote, via the intraperitoneal route. The results suggest that the source of the inoculum and the route of inoculation remarkably influence the evolution of the infection for the T. cruzi in the vertebrate host even when the same strain of the parasite is used. Key-words: Trypanosoma cruzi. Inoculation route. Blood trypomastigotes. Metacyclic trypomastigotes. Dog model.

Resumo Neste trabalho foi avaliada a influência da fonte do inóculo (tripomastigota sangüíneo ou metacíclico) e da via de inoculação (intraperitoneal ou conjuntival) na evolução da infecção de cães pelas cepas Berenice62 e Berenice-78 do Trypanosoma cruzi. O índice de infectividade e os níveis de parasitaemia foram significativamente influenciados pelas condições de inoculação, tendo sido maiores nos animais inoculados pela via conjuntival, com tripomastigotas metacíclicos. Por outro lado, não foi observada relação entre as condições de inóculo e as lesões teciduais nos animais infectados com a cepa Berenice-78, pois todos apresentaram miocardite aguda severa. De forma inversa, nos animais infectados com a cepa Berenice-62, foi observada miocardite aguda intensa apenas nos cães inoculados com tripomastigotas metacíclicos, via intraperitoneal. Estes resultados sugerem que a taxa de infectividade e a evolução da infecção do hospedeiro vertebrado pelo T. cruzi podem ser marcadamente influenciadas pela fonte do inóculo e pela via de inoculação, mesmo quando a mesma cepa do parasita é utilizada.
\end{abstract}

Palavras-chaves: Trypanosoma cruzi. Via de inoculação. Tripomastigota sanguíneo. Tripomastigota metacíclico. Modelo cão.

\footnotetext{
1. Departamento de Ciências Biológicas, Instituto de Ciências Biológicas da Universidade Federal de Ouro Preto. 2 Departamento de Patologia Geral, Instituto de Ciências Biológicas da Universidade Federal de Minas Gerais. 3. Departamento de Análises Clínicas, 4.Departamento de Farmácia da Escola de Farmácia da Universidade Federal de Ouro, Ouro Preto, MG.

Address to: Profa Maria Terezinha Bahia. Dept ${ }^{0}$ de Ciências Biológicas/ICB/UFOP, Campus Universitário, Morro do Cruzeiro, $35400-000$ Ouro Preto, MG, Brazil.

E-mail: mtbahia@nupeb.ufop.br

Recebido para publicação em 20/7/2001.
} 
Trypanosoma cruzi develops a complex biological cycle involving mammal hosts and triatomine bugs. During this cycle, distinct forms with varying morphology and functions can be observed. Amastigotes and epimastigotes are the division stages observed in mammal cells and in the intestinal tract of the triatomine bugs, respectively. Blood (BT) and metacyclic trypomastigotes (MT) are the infective stages encountered in mammals and triatomine excretions. The natural infection of mammals begins when the triatomines, after a blood meal deposit the MT in the host skin or mucous membrane. These trypomastigotes can penetrate through the mucous membrane, especially the ocular one or through the skin lesion caused by the insect bite.

There are many other mechanisms of $T$. cruzi transmission, including congenital, blood transfusion, laboratorial accidents and oral infection. Regardless of the mechanism of transmission, the host and parasite interaction begins after contact with BT or MT. It seems that only these stages are equipped with important molecules necessary for the interaction and/or host cell invasion ${ }^{14}$. Apparently, MT has a greater ability than BT to penetrate the oral mucosa of mice ${ }^{7}$.
Many factors related with the parasite (genetic variability, inoculum, virulence, infectivity, pathogenicity) and host (species, age, sex, nutrition, concomitant infections, immunity, etc) or the conditions of the inoculation are involved in the course of the disease in experimental models ${ }^{18}$. Another point that should be considered is that different trypomastigotes surface proteins may differ considerably in their conformational structure, although with similarity in their sequences ${ }^{16}$. Possibly different trypomastigote forms and T. cruzi strains use a different repertory of membrane components for penetration into the host cell. Recent studies indicate that differences in GPI mucin structure present in metacyclic and blood trypomastigotes may influence their interaction with vertebrate host cells and consequently in the development of the host immune response and inflammatory process during the early stage of acute infection².

A previous study on canine trypanosomiasis showed that the infectivity and parasitaemia of $T$. cruziBerenice62 and Berenice-78 strains were similar when the conditions of the inoculum were the same ${ }^{10}$. This paper aimed to verify the influence of the inoculum source (blood or metacyclic trypomastigote) and the route of inoculation (intraperitoneal or conjunctival) on the evolution of $T$. cruzi infection in dogs.

\section{MATERIAL AND METHODS}

Trypanosoma cruzi strains. T. cruzi strains, Berenice- $62^{15}$ and Berenice- $78^{8}$, both isolated from the patient Berenice, the first human case of Chagas' disease ${ }^{4}$ characterized as $T$. cruzi $\|^{913}$.

Experimental animals and infection. Eight groups of mongrel dogs, two months old were used. Animals were raised in the kennel of the Federal University of Ouro Preto, MG, Brazil. Dogs were fed with commercial chow and water was available ad libitum. Before the experiments, dogs were treated with anthelmintic and immunized against infectious diseases.

The animals were inoculated via intraperitoneal (IP) or conjunctival (CO) routes with 2000 blood (BT) or metacyclic (MT) trypomastigotes per $\mathrm{kg}$ bodyweight of the Berenice-62 or Berenice-78 strains made as described in Table 1. BT from mice (peak of parasitaemia) and MT from experimentally infected Triatoma infestans were used as inoculum.

To verify whether components of blood or triatomine feces influence the trypomastigote infectivity, three dogs were inoculated with $\mathrm{BT}$, through $\mathrm{CO}$ route, rapidly washed by centrifugation and diluted in PBS, $\mathrm{pH} 7.2$ and three other animals with BT washed in PBS, pH 7.2 and diluted in feces and urine of triatomines.

Parameters evaluated. Parasitaemia curves: parasitaemia was followed from the $10^{\text {th }}$ day of infection up to negativation by fresh blood collected from the marginal ear vein. Parasites were counted according to the technique proposed by Brener ${ }^{1}$, and the parasitaemia curves represent the mean value from all infected dogs at each time point.

Hemoculture: was performed only from sample of dogs without parasites in fresh blood examination. The technique was processed ${ }^{5}$ using $10 \mathrm{ml}$ of blood and examined monthly up to 120 days for the presence of T. cruzi parasites.

Serological profile: For serological tests the blood was collected 40 days after inoculation. Sera obtained were stored at $-20^{\circ} \mathrm{C}$ and ELISA tests performed according to Voller et $a^{R 0}$, using antigen obtained from the $Y$ strain of $T$. cruzi cultivated in LIT medium and peroxidase conjugated goat anti-dog IgG (Sigma Co. Ltd). The cut-off value was determined using the mean absorbance from ten uninfected animals plus two standard deviations.

Histopathological examinations. For histopathological evaluation animals were necropsied during the acute phase (30 to 40 days after inoculation). Fragments of the heart were fixed in $10 \%$ buffered formalin, $\mathrm{pH} 7.2$, routinely processed and included in paraffin. Five $\mathrm{mm}$ thick sections were stained with Hematoxylin-Eosin. Intensity of parasitism and inflammatory lesions were comparatively analyzed in sections of the right atrium. This tissue was chosen due to previous studies demonstrating that the strains studied here possess special tropism to this region of the heart.

Statistical analysis. To compare the rates of infectivity the $\mathrm{X}^{2}$ test was used. The parasitaemia was 
analyzed by a non-parametric test ${ }^{6}$ that compares the area under the curve of parasitaemia. The pre-patent period and patent period were compared using analysis of variance ${ }^{17}$.

\section{RESULTS}

Table 1 shows the serological (ELISA test) and parasitological results of dogs inoculated with BT and MT of $T$. cruzi via IP and CO routes. Dogs with positive parasitological and serological tests were considered infected. ELISA results were always in agreement with the parasitological examinations. The rates of infectivity were very similar in animals infected with both $T$. cruzi strains inoculated under the same conditions. All animals inoculated via IP route were infected (100\%) independently of the $T$. cruzi strain, source of trypomastigote and route of inoculation used. Dogs inoculated with MT of both strains by CO showed $88.9 \%$ of infectivity, however the rates of infectivity were significantly $(p<0.05)$ lower when BT of Berenice-62 (11.1\% of infectivity) and Berenice-78 (0\% of infectivity) strains were inoculated using the same route. No infection was detected in animals inoculated via $\mathrm{CO}$ route with $\mathrm{BT}$ washed with $\mathrm{PBS}, \mathrm{pH} 7.2$ or diluted in feces and urine of triatomines

Figure 1 shows the mean of parasitaemia of dogs inoculated with the Berenice-62 strain. Animals inoculated with $\mathrm{MT} / \mathrm{CO}$ showed significantly higher

Table 1 - Experimental conditions, serological, parasitological and infectivity data of dogs inoculated with blood or metacyclic trypomastigotes of Trypanosoma cruzi Berenice-62 and Berenice-78 strains, via intraperitoneal and conjunctival routes.

\begin{tabular}{lcccc}
\hline T. cruzistrains & $\begin{array}{c}\text { Source of inoculum/(+) } \\
\text { Inoculation route }\end{array}$ & $\begin{array}{c}\text { ELISA/(+) } \\
\text { dogs inoculated }\end{array}$ & $\begin{array}{c}\text { Parasitological } \\
\text { test/ dogs examined }\end{array}$ & $\begin{array}{c}\text { Infectivity } \\
(\%)\end{array}$ \\
\hline Be-62 & & & & \\
& $\mathrm{BT} / \mathrm{IP}$ & $6 / 6$ & $6 / 6$ & 100.0 \\
$\mathrm{BT} / \mathrm{CO}$ & $1 / 9$ & $1 / 9$ & 11.1 \\
$\mathrm{MT} / \mathrm{IP}$ & $6 / 6$ & $6 / 6$ & 100.0 \\
& $\mathrm{MT} / \mathrm{CO}$ & $8 / 9$ & $8 / 9$ & 88.9 \\
\hline $\mathrm{Be}-78$ & & & $6 / 6$ & 100.0 \\
& $\mathrm{BT} / \mathrm{IP}$ & $6 / 6$ & $0 / 16$ & 0 \\
& $\mathrm{BT} / \mathrm{CO}$ & $6 / 16$ & $8 / 6$ & 100.0 \\
& $\mathrm{MT} / \mathrm{IP}$ & $8 / 6$ & $8 / 9$ & 88.9 \\
\hline
\end{tabular}

BT - blood trypomastigotes

MT - metacyclic trypomastigotes

IP - intraperitoneal route

$\mathrm{CO}-$ conjunctival route

$X^{2}<0.05$

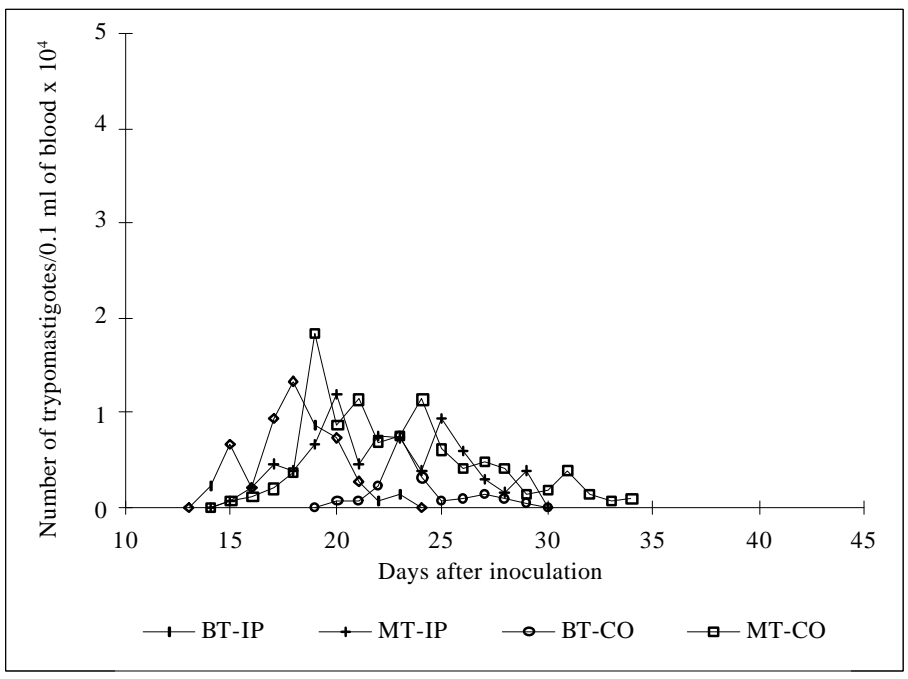

Figure 1 - Mean parasitaemia of dogs inoculated with blood (BT) or metacyclic trypomastigotes (MT) of Trypanosoma cruzi Berenice-62 strain via intraperitoneal (IP) or conjunctival (CO) route during the acute phase of the infection. 
parasitaemia $(p<0.05)$ than animals inoculated with BT despite the inoculation route.

Figure 2 shows the mean of parasitaemia of dogs inoculated with MT or BT from the Berenice-78 strain.
Parasitaemia was significantly higher $(p<0.05)$ in animals inoculated with MT independent of the route of inoculation, but especially when $\mathrm{CO}$ route was used. No infection was detected in animals inoculated with BT by $\mathrm{CO}$ route.

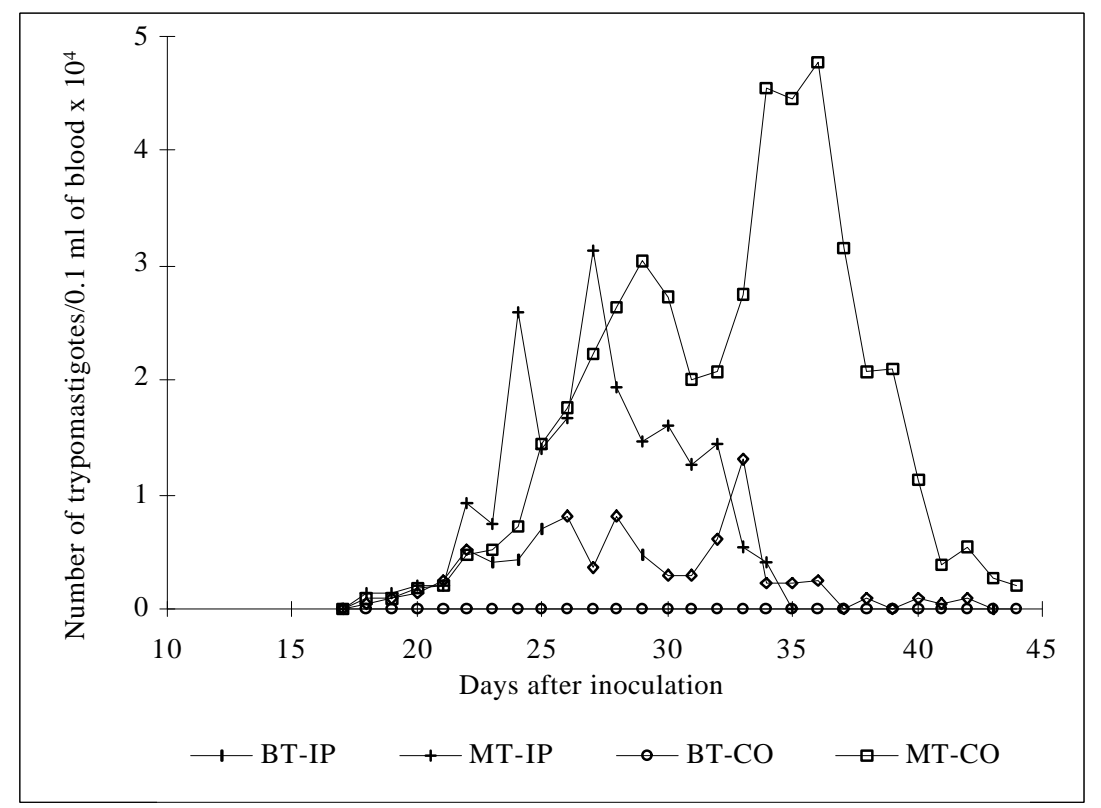

Figure 2 - Mean parasitaemia of dogs inoculated with blood (BT) or metacyclic trypomastigotes (MT) of Trypanosoma cruzi Berenice-78 strain via intraperitoneal (IP) or conjunctival (CO) route during the acute phase of the infection.

The parasitaemia of animals infected with MT of the Berenice-78 strain was significantly higher $(p<0.05)$ than the observed in all dogs infected with the Berenice-62. No significant difference of parasitaemia among the strains was observed when dogs were infected with BT/ IP.This comparison was not possible when animals were inoculated with BT/CO because only one dog inoculated with Berenice-62 was infected.
The results of pre-patent and patent periods are shown in Table 2. Difference of pre-patent period was observed only among dogs inoculated with the Berenice62 strain (BT/CO). The patent periods were significantly longer $(p<0.05)$ only in dogs inoculated with MT by CO route of both T. cruzi strains. Exactly in these situations, a tendency for more variation in the pre-patent period was observed.

Table 2 - Pre-patent period and patent period of dogs inoculated with blood or metacyclic trypomastigotes of Trypanosoma cruzi Berenice-62 and Berenice-78 strains via intraperitoneal and conjunctival routes.

\begin{tabular}{|c|c|c|c|c|c|c|c|c|}
\hline \multirow{3}{*}{$\begin{array}{l}\text { Source of inoculum/ } \\
\text { Route of inoculation }\end{array}$} & \multicolumn{8}{|c|}{ Trypanosoma cruzi strains } \\
\hline & \multicolumn{4}{|c|}{ Berenice-62 } & \multicolumn{4}{|c|}{ Berenice-78 } \\
\hline & $\mathrm{BT} / \mathrm{IP}$ & $\mathrm{BT} / \mathrm{CO}$ & $\mathrm{MT} / \mathrm{IP}$ & $\mathrm{MT} / \mathrm{CO}$ & $\mathrm{BT} / \mathrm{IP}$ & $\mathrm{BT} / \mathrm{CO}$ & $\mathrm{MT} / \mathrm{IP}$ & $\mathrm{MT} / \mathrm{CO}$ \\
\hline PPP (DAI) & $13(13-16)$ & $18^{a / b}(18)$ & $14(13-16)$ & $14(14-17)$ & $18(18-22)$ & $\mathrm{NI}$ & $17(17-21)$ & $17(17-23)$ \\
\hline $\mathrm{PP}(\mathrm{DAl})$ & $23(21-23)$ & $28^{b}(28)$ & $29(25-29)$ & $42^{\mathrm{a}}(22-42)$ & $41(27-41)$ & $\mathrm{NI}$ & $34(21-34)$ & $50^{\mathrm{a}}(29-50)$ \\
\hline
\end{tabular}

DAl: days after inoculation

PPP - pre-patent period; PP patent period

BT - blood trypomastigotes

MT - metacyclic trypomastigotes

IP - intraperitoneal route

$\mathrm{CO}$ - conjunctival route

$\mathrm{NI}$ - not infected

a $-p<0.05$

b - one animal infected 
Histopathological analysis of the right atrium of dogs infected with $T$. cruzi Berenice-62 strain showed mild lesions (Figure 3 ) when infected with BT, moderate lesions when infected with MT/CO and severe lesions only when

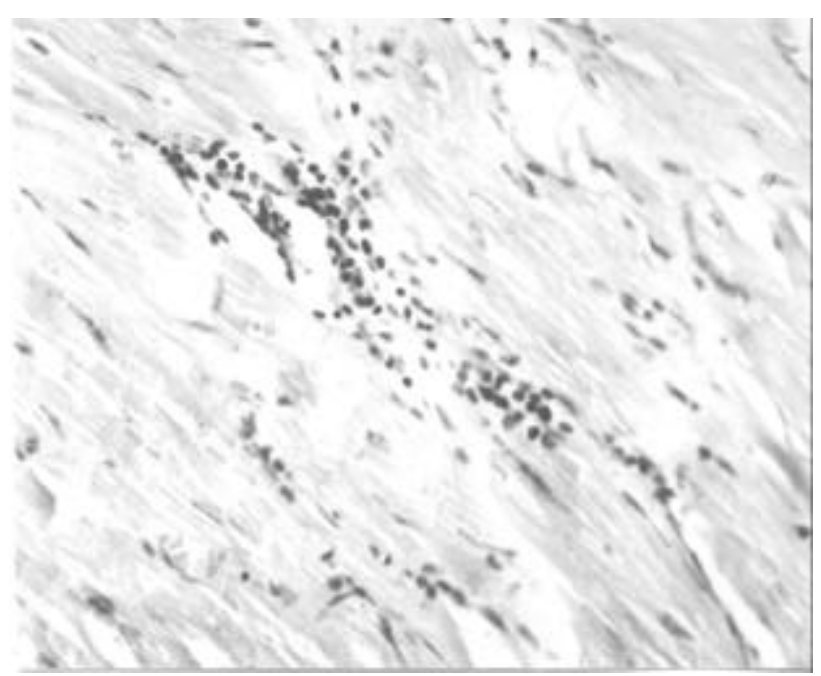

Figure 3 - Right atrium (myocardium) of dogs inoculated with blood trypomastigotes of Trypanosoma cruzi Berenice-62 via intraperitoneal route. Mild acute myocarditis with rare mononuclear cells is observed (HE $\times 660$ ). infected with MT/IP. All dogs infected with T. cruziBerenice78 strain always showed severe lesions (Figure 4), independently of the inoculation route used. No infection was detected in animals inoculated with BT/CO.

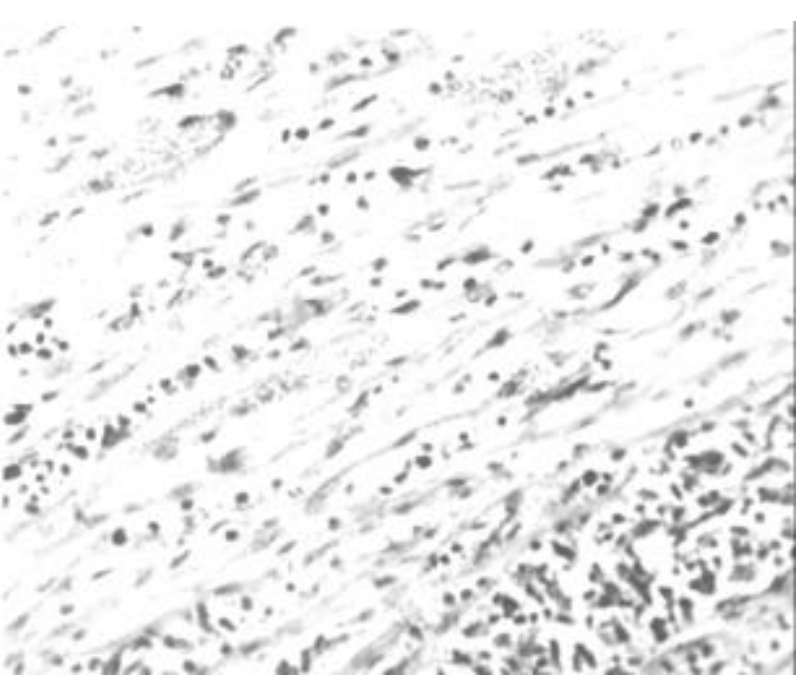

Figure 4 - Right atrium (myocardium) of dogs inoculated with metacyclic trypomastigotes of Trypanosoma cruzi Berenice-78 via conjunctival route. Severe acute myocarditis with exudate of mononuclear cells can be observed (HE x 660).

\section{DISCUSSION}

The rates of infectivity in dogs inoculated with $T$. cruzi Be-62 and Be-78 strains were very similar when the conditions of inoculation were the same. However, the experiments clearly showed a great difference of infectivity between BT and MT by CO route in relation to IP route regardless of the $T$. cruzi strains used. The demonstration of the inferior capacity of BT in relation to MT to invade the mucosa has been previously described and it was demonstrated that MT were 200 times more efficient in penetrating the oral mucosa of mice than $\mathrm{BT}^{7}$. On the other hand, McHardy and $\mathrm{Neal}^{12}$, demonstrated that mice immunized with vaccines prepared from freeze-thawed or ultra-sonicated epimastigotes, blood trypomastigotes, or plasma antigen, of T.cruzistrains and challenged by the injection of blood trypomastigotes killed more rapidly than the inoculated with bug-derived trypomastigotes.

Our results showed that these differences are probably not dependent on the components normally present in the blood or feces and triatomine urine. It was demonstrated that BT washed with PBS or mixed with feces and triatomine urine were not able to penetrate ocular mucosa of dogs.

These differences of infectivity are not surprising if the natural mechanisms of Chagas' disease infection are considered. In natural conditions the infection with BT occurs by blood transfusion, congenital transmission, carnivorism or breast-feeding. Except in carnivorism and breast-feeding, a very unlikely mechanism of transmission ${ }^{21}$, there is no interaction of the BT with the mucosa during the infection. Thus the inoculation of BT by $\mathrm{CO}$ route is artificial and was, in our experimental conditions, unable or inefficient to infect dogs $(0$ and $11.1 \%)$. However, when BT are inoculated directly in the peritoneum they infect $100 \%$ of the animals.

In contrast, the infection with MT in natural conditions occurs by deposition of the parasites by the triatomines on the skin and penetration via the skin bite or by $\mathrm{CO}$ route. Thus, the inoculation of dogs with MT by CO route represents the natural process of Chagas' disease transmission in rural area by triatomines and our results reinforce the great success of MT to invade mucosa. Finally, the results also confirm the higher infectivity of MT $(88.9 \%$ and $100 \%)$ in relation of BT, independently of the route of inoculation used.

Although the differences between BT and MT are relatively well known, especially in relation to membrane constituents, the real nature of their ability to infect ocular mucosa, reported in this work, as well as oral mucosa ${ }^{7}$ has not been determined. MT has biological and biochemical characteristics probably not shared with BT, which could be fundamental in mucosa invasion. The enlargement of the patent period in dogs inoculated with MT of both strains by CO route, larger than that observed with IP inocula, suggests the development of different tissue-parasite interactions dependent on the compartment where the infection begins. The long prepatent period observed in dogs inoculated with BT/CO may indicate the difficulty of this parasite stage in 
penetrating the conjunctival mucosa. Differences in the infectivity between BT/CO and MT/CO could be due to the greater capacity of MT in resisting to the immune defense mechanisms present in the ocular mucosa. When both types of trypomastigotes were inoculated in dogs through IP route the rates of infectivity were the same (100\%).

The results showed also the influence of the source of the inoculum and route of inoculation on the parasitaemia of the dogs. Animals inoculated with MT/ $\mathrm{CO}$ always displayed higher levels of parasitaemia when infected with both $T$. cruzi strains. Although the histopathological data have not been quantified, it was demonstrated that all animals inoculated and infected with Be-78 strain always showed severe acute myocarditis. Similar lesion, with Berenice-78 strain, only occurred in dogs infected with MT/CO. This event, in addition to the histopathological data observed in both strains, evidenced more virulence and pathogenicity in MT than BT forms.

Previous studies, comparing the pathogenicity between MT/CO from Berenice-62 and Berenice-78, showed higher parasitaemia and histopathological lesions in dogs infected with Berenice-78 ${ }^{10}$. This strain, when applied intraperitoneally, also provoked more severe acute myocarditis ${ }^{3}$ and more chronic lesions than the former ${ }^{11}$.

In conclusion, the results of this work indicate that the pathogenicity in $T$. cruzi infection in the vertebrate host, specifically in dogs, depends on the strain, source of the inoculum and route of inoculation. The work points out to the importance to determine the molecules that take part in host-parasite interface in the site of T. cruzi entry into specific organs and cells, and to define what characteristics of each natural and experimental compartment are used to establish the infection.

\section{ACKNOWLEDGEMENTS}

This work was supported by grants from the Fundação de Amparo à Pesquisa do Estado de Minas Gerais (FAPEMIG), Universidade Federal de Ouro Preto (UFOP) and Conselho Nacional de Desenvolvimento Científico e Tecnológico (CNPq). We also thank Dr Luiz Carlos Crocco Afonso for his assistance in the language revision and Maria Chaves for histopathological preparations.

\section{REFERENCES}

1. Brener Z. Therapeutic activity and criterion of cure on mice experimentally infected with Trypanosoma cruzi. Revista do Instituto de Medicina Tropical de São Paulo 4: 189-196, 1962.

2. Brener Z, Gazinelli RT. Immunological control of Trypanosoma cruzi infection and pathogenesis of Chagas' disease. International Archive of Allergy and Immunology 114: 103-110, 1997.

3. Caliari MV, Lana M, Caliari ER, Tafuri WL. Cardiac plexus of dogs experimentally infected with Trypanosoma cruzi: inflammatory lesions and quantitation studies. Revista da Sociedade Brasileira de Medicina Tropical 28: 13-17,1995.

4. Chagas C 1909. Nova tripanosomíase humana. Estudos sobre a morfolojia e ciclo evolutive do Schizotrypamim cruzi n. gen., n. sp., ajente etiolojico de nova entidade morbida do homem. Memórias do Instituto Oswaldo Cruz 1: 159-218, 1909.

5. Chiari E, Dias JCP, Lana M, Chiari CA. Hemocultures for the parasitological diagnosis of human chronic Chagas' disease. Revista da Sociedade Brasileira de Medicina Tropical 21: 19-23, 1989.

6. Conover WJ. Practical non Parametric Statistic. $7^{\text {th }}$ edition, John Wiley and Sons, New York, 1980.

7. Hoft DF. Differential mucosal infectivity of different life stages of Trypanosoma cruzi. American Journal of Tropical Medicine and Hygiene 55: 360-364, 1996.

8. Lana M, Chiari CA. Caracterização biológica comparativa das cepas Berenice-62 e Berenice-78 de Trypanosoma cruzi, isoladas da mesma paciente em diferentes períodos. Memórias do Instituto Oswaldo Cruz 81: 247-253, 1986.

9. Lana M, Chiari CA, Chiari E, Morel CM, Goncalves AM, Romanha AJ. Characterization of two isolates of Trypanosoma cruzi obtained from the patient Berenice, the first human case of Chagas' disease described by Carlos Chagas in 1909. Parasitology Research 82: 257-260, 1996.
10. Lana M, Chiari E, Tafuri WL. Experimental Chagas' disease in dogs. Memórias do Instituto Oswaldo Cruz 87: 59-71, 1992.

11. Lana M, Tafuri WL, Caliari MV, Bambirra EA, Chiari CA, Barbosa AJA, Toledo MJO, Chiari E. Fase crônica cardíaca fibrosante da tripanosomiase cruzi experimental no cão. Revista da Sociedade Brasileira de Medicina Tropical 21: 113-121,1988.

12. McHardy N, Neal RA. A comparison of challenge with Trypanosoma cruzi blood- stream trypomastigotes and metacyclic trypomastigotes from Rhodnius prolixus in mice immunized with killed antigens. Transactions of the Royal Society of Tropical Medicine and Hygiene 73: 409-14, 1979.

13. Momen $\mathrm{H}$. Taxomomy of Trypanosoma cruzi: a commentary on characterization and nomenclature. Memórias do Instituto Oswaldo Cruz 94: 181-184, 1999.

14. Ramirez MMI, Ruiz RC, Araya JE, Da Silveira JF, Yoshida N. Involvement of the stage-specific 82-kilodalton adhesion molecule of Trypanosoma cruzi metacyclic trypomastigotes in host cell invasion. Infection and Immunity 61: 3636-3641, 1993.

15. Salgado JA, Garcez PN, Oliveira CA, Galizzi J. Revisão clinica atual do primeiro caso humano descrito de doença de Chagas. Revista do Instituto de Medicina Tropical de São Paulo 4: 330-337, 1962.

16. Santori FR, Dorta ML, Juliano L, Juliano MA, da Silveira JF, Ruiz RC, Yoshida, N. Identification of a domain of Trypanosoma cruzi metacyclic trypomastigote surface molecule gp82 required for attachment and invasion of mammalian cells. Molecular Biochemistry and Parasitology 78: 209-216, 1996.

17. Snedecor GM, Cochran WG. Statistical Methods. $7^{\text {th }}$ edition. The lowa State University Press, Ames, lowa, 1989.

18. Souza W. O parasito e sua interação com os hospedeiros. In: Brener Z, Andrade Z, Barral-Netto M (eds) Trypanosoma cruzi e 
doença de Chagas, $2^{\text {nd }}$ edition Guanabara Koogan, Rio de Janeiro p. 88 - 126, 1999.

19. Vitor RWA, Chiari E. Avaliação de antígenos do Trypanosoma cruzi para a reação de hemaglutinação indireta. Revista do Instituto de Medicina Tropical de São Paulo 178-182, 1987.

20. Voller A, Bidwell DE, Bartlett A. Enzyme immunoassays in diagnostic medicine. Theory and practice. Bulletin of the World Health Organization 53: 55-65, 1982.
21. World Development Report. Control of Chagas' disease. Report a WHO Expert Committee, Geneva. World Health Organization Technical Report Series 811, 1991. 